\title{
Expression of DNA double-strand break repair proteins predicts the response and prognosis of colorectal cancer patients undergoing oxaliplatin-based chemotherapy
}

\author{
KEISUKE IHARA $^{1}$, SATORU YAMAGUCHI ${ }^{1}$, NOZOMI UENO ${ }^{1}$, YUKIKO TANI ${ }^{1}$, YOSUKE SHIDA ${ }^{1}$, \\ HIDEO OGATA $^{1}$, YASUSHI DOMEKI ${ }^{1}$, KENTARO OKAMOTO ${ }^{1}$, MASANOBU NAKAJIMA ${ }^{1}$, \\ KINRO SASAKI $^{1}$, TAKASHI TSUCHIOKA ${ }^{1}$, HIROYUKI MITOMI ${ }^{2}$ and HIROYUKI KATO ${ }^{1}$ \\ ${ }^{1}$ Department of Surgical Oncology, and ${ }^{2}$ Department of Surgical and Molecular Pathology, \\ Dokkyo Medical University, Mibu, Shimotsuga, Tochigi 321-0293, Japan
}

Received July 14, 2015; Accepted September 16, 2015

DOI: 10.3892/or.2015.4488

\begin{abstract}
DNA intrastrand cross-linking agents such as oxaliplatin induce DNA double-strand breaks (DSBs) during DNA repair and replication. In the present study, we hypothesized that DNA intrastrand cross-linking agents may significantly benefit colorectal cancer patients with deficiencies in DSB repair. Seventy-eight patients with metastatic or recurrent colorectal cancer who had measurable target lesions and who underwent resection for primary colorectal cancer in our institution between April 2007 and March 2013 were included in the present study. The median age was 64.5 years, and the cohort consisted of 49 males and 29 females. The median progressionfree survival (PFS) was 10.9 months. The expression of DSB repair proteins such as RAD51 and MRE11 was investigated by immunohistochemistry, and associations between RAD51 and MRE11 expression and clinicopathological factors or chemotherapeutic effect were assessed. MRE11-negative cases and RAD51-negative cases achieved significantly better tumor reduction compared with cases with positive expression. Cases with negative expression of both proteins or negative expression of either protein had significantly longer PFS than cases with positive expression for both proteins. In conclusion, DSB repair protein expression-negative colorectal cancer cases may be more highly sensitive to chemotherapy, and thus DSB repair protein expression may be a useful prognostic indicator for colorectal cancer patients.
\end{abstract}

Correspondence to: Dr Keisuke Ihara, Department of Surgical Oncology, Dokkyo Medical University, 880 Kitakobayashi, Mibu, Shimotsuga, Tochigi 321-0293, Japan

E-mail: k-ihara@dokkyomed.ac.jp

Key words: colorectal cancer, immunohistochemistry, DSB repair protein expression pattern, MRE11, RAD51

\section{Introduction}

Remarkable progress has been made in chemotherapy for colorectal cancer during the last decade. Currently, standard first-line treatments for unresectable advanced or recurrent colorectal cancer include fluorouracil with irinotecan or oxaliplatin, alone or in combination with molecular-targeted agents, such as the monoclonal antibody against vascular endothelial growth factor (VEGF) and epidermal growth factor receptor (EGFR) $(1,2)$. Combinations of drug therapies in unresectable advanced or recurrent colorectal cancer patients has prolonged the survival time to more than 30 months (3-5), but the therapeutic effects vary depending on each case. Thus, it is important to predict the chemotherapeutic effect and select patients who will benefit from cancer chemotherapy. Several studies have shown that various biomarkers predict the sensitivity to chemotherapy or chemoradiation therapy. The presence of microsatellite instability (MSI) and mutations of the KRAS gene are reliable biomarkers for sensitivity to fluorouracil and anti-EGFR monoclonal antibodies, respectively $(5,6)$. However, there is no reliable biomarker for oxaliplatin and irinotecan.

DNA intrastrand cross-linking agents such as oxaliplatin induce DNA double-strand breaks (DSBs) during the process of DNA replication and repair (7). BRCA1, 2, the MRE11-RAD50-NBS1 (MRN) complex and RAD51 play an important role in homologous recombination during DSB repair. A previous study showed that DNA damage repair competence varies among individual breast tumors, and is closely correlated with chemosensitivity (8). The Fanconi anemia-BRCA pathway plays an important role in restoring cytotoxic damage by anticancer agents and radiation $(9,10)$. Furthermore, previous studies have shown that BRCA-associated cancer is particularly sensitive to DNA interstrand cross-linking agents such as mitomycin $\mathrm{C}$ or platinum-based drugs $(11,12)$. Differences in the expression of DNA DSB repair proteins (DDRPs) among individual colon cancer cases may also be related to the sensitivity to treatment, as well as breast cancer.

MRE11 forms the core of the MRN complex, which has essential roles in detection, signaling, protection and repair of 
DSBs $(13,14)$. RAD51 is an important factor in homologous recombination as well as MRE11, and is a predictive factor for chemoradiotherapy response in a variety of human cancers. Moreover, overexpression of RAD51 confers resistance to DNA interstrand cross-linking agents such as cisplatin in nonsmall cell lung cancer (15-17).

In the present study, we hypothesized that DNA intrastrand cross-linking agents may significantly benefit colorectal cancer patients with deficiencies in DSB repair. We investigated the expression of MRE11 and RAD51 by immunohistochemistry. Associations between expression and therapeutic effect in colorectal cancer patients were also explored.

\section{Materials and methods}

Patients. Seventy-eight patients with metastatic or recurrent colorectal cancer who had measurable target lesions such as hepatic, pulmonary, lymphatic and peritoneal metastases, underwent resection for primary colon and rectal cancer at our institution between April 2007 and March 2013. All patients underwent combination chemotherapy including oxaliplatin.

Assessments of therapeutic effect. Descriptions of the therapeutic effects were evaluated using the best overall response to first-line chemotherapy using RECIST version 1.1. Changes in tumor size were expressed as the relative change in the sum of the longest diameters of the target lesions. Non-target lesions and newly occurring lesions were not considered in the measurement of tumor size changes (18). The endpoints of the long-term outcome study were progression-free survival (PFS). PFS was calculated by progression of target lesions as the only events for survival analyses.

Immunohistochemistry. Five-micrometer sections were deparaffinized with xylene and rehydrated with alcohol, and placed in $0.1 \mathrm{M} \mathrm{NaOH}$ citrase buffer ( $\mathrm{pH}$ 7.0) for RAD51 immunostaining or $0.01 \mathrm{M} \mathrm{NaOH}$ citrate buffer ( $\mathrm{pH}$ 6.0) for MRE11 immunostaining, and heated in an autoclave at $121^{\circ} \mathrm{C}$ for $15 \mathrm{~min}$. Sections were then preincubated with $3 \% \mathrm{H}_{2} \mathrm{O}_{2}$ in methanol for $30 \mathrm{~min}$ at room temperature to quench endogenous peroxidase activity. After blocking with normal goat serum, the sections were incubated with mouse anti-RAD51 3C10 monoclonal antibody (1:800; clone 51RAD01; Thermo Scientific, Fremont, CA, USA) and mouse anti-MRE11 12D7 monoclonal antibody (1:1600; ab214; Abcam, Cambridge, $\mathrm{UK})$ for $60 \mathrm{~min}$ at $4^{\circ} \mathrm{C}$. Thereafter, the sections were incubated with a secondary antibody (Vectastain Elite ABC kit; Vector Laboratories, Burlingame, CA, USA) for $30 \mathrm{~min}$, washed with phosphate-buffered saline (PBS) and treated with peroxidase-conjugated streptavidin for $30 \mathrm{~min}$. The sections were visualized by incubation with diaminobenzidine tetrahydrochloride (Liquid DAB+ Substrate Chromogen System; Dako, Carpinteria, CA, USA) and counterstained with hematoxylin.

Evaluation of immunohistochemical staining. Immunohistochemistry (IHC) scores for $<10 \%$ of nuclear staining in cancer cells were negative, whereas those cases with IHC scores for $>10 \%$ stained cells were deemed positive.
Table I. Clinicopathological characteristics of the patients $(\mathrm{n}=78)$.

\begin{tabular}{lc} 
Factors & Date \\
\hline Median age (years) & 64.5 \\
Gender, $\mathrm{n}$ & \\
Men & 49 \\
Female & 29 \\
Location, $\mathrm{n}$ & \\
Proximal & 20 \\
Distal & 58 \\
Median tumor size (mm) & 50 \\
Histology, n & \\
Well differentiated & 25 \\
Moderately differentiated & 44 \\
Poorly differentiated & 4 \\
Others & 5
\end{tabular}

Site of metastases, $\mathrm{n}$

Liver $\quad 44$

Lung $\quad 21$

Peritoneum 11

Lymph node $\quad 8$

Bone 1

Regimen, $n$

mFOLFOX6 + bevacizumab $\quad 50$

CapeOX + bevacizumab 20

mFOLFOX6 7

CapeOX 1

Treatment cycles, mean number $\quad 10$

Median overall survival (months) $\quad 32.5$

Median progression-free survival (months) $\quad 10.9$

Statistical analysis. Categorical analysis of variables was performed using either the Chi-square or Fisher's exact test, as appropriate. Continuous data were compared with the Mann-Whitney U test. Survival curves were plotted according to the Kaplan-Meier method, and any differences were analyzed using the log-rank test. A multivariate analysis with Cox proportional hazards model was adopted to clarify the independent prognostic factors. Differences were considered to be significant if the P-value was $<0.05$. All statistical analyses were carried out using the R software (version 3.1.1).

\section{Results}

Patient clinicopathological characteristics. Patient clinical characteristics are detailed in Table I. The median age was 64.5 years, and the cohort consisted of 49 males and 29 females. Most patients received combination chemotherapy in addition to bevacizumab $(n=70,90 \%)$. Fifty patients received mFOLFOX6 + bevacizumab and 20 patients received CapeOX + bevacizumab. The median PFS was 10.9 months. 


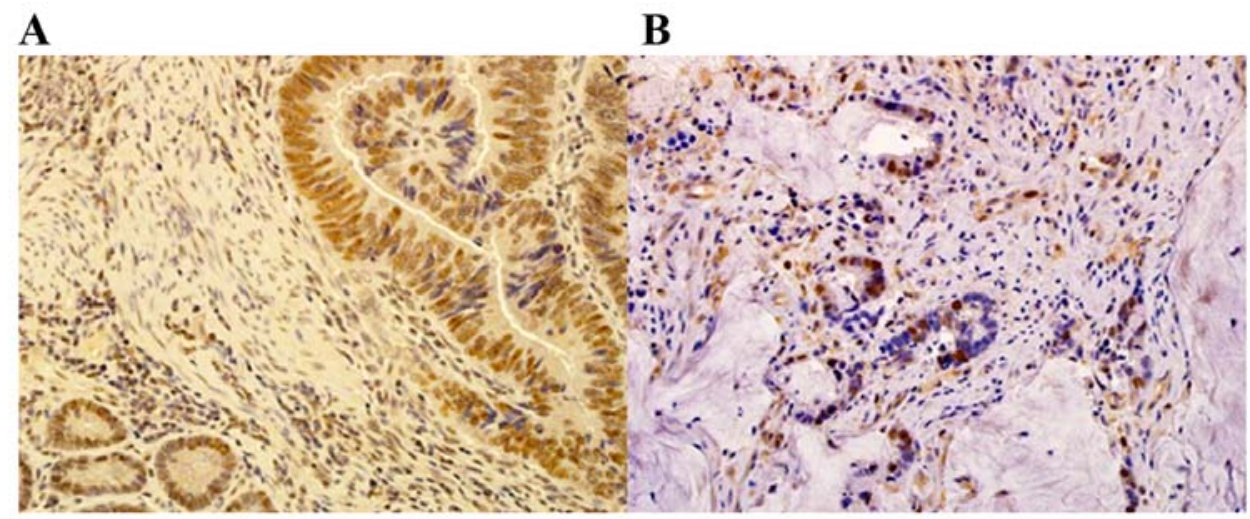

Figure 1. MRE11 and RAD51 expression in colorectal cancer tissues as assessed by immunohistochemistry. (A) MRE11 was stained in the nucleus in the cancer cells (magnification, $\mathrm{x} 400$ ). (B) RAD51 was stained in the nucleus in the cancer cells (magnification, $\mathrm{x} 400$ ).

Table II. Relationship between DDRP expression and clinicopathological characteristics of the patients $(\mathrm{n}=90)$.

\begin{tabular}{|c|c|c|c|c|c|c|}
\hline \multirow[b]{2}{*}{ Factors } & \multicolumn{2}{|c|}{ MRE11 } & \multirow[b]{2}{*}{ P-value } & \multicolumn{2}{|c|}{ RAD51 } & \multirow[b]{2}{*}{ P-value } \\
\hline & $\begin{array}{l}\text { Negative } \\
(\mathrm{n}=30)\end{array}$ & $\begin{array}{c}\text { Positive } \\
(\mathrm{n}=48)\end{array}$ & & $\begin{array}{c}\text { Negative } \\
(\mathrm{n}=38)\end{array}$ & $\begin{array}{c}\text { Positive } \\
(\mathrm{n}=40)\end{array}$ & \\
\hline Median age (years) & 64 & 65.5 & 0.2 & 64 & 67 & 0.3 \\
\hline \multicolumn{7}{|l|}{ Gender } \\
\hline Male & 15 & 34 & 0.064 & 26 & 23 & 0.3 \\
\hline Female & 15 & 14 & & 12 & 17 & \\
\hline \multicolumn{7}{|l|}{ Location } \\
\hline Proximal & 10 & 10 & 0.2 & 9 & 11 & 0.7 \\
\hline Distal & 20 & 38 & & 29 & 29 & \\
\hline Median tumor size (mm) & 55 & 50 & 0.4 & 55 & 50 & 0.2 \\
\hline Median treatment cycles & 11.5 & 9.5 & 0.2 & 11.5 & 8 & 0.1 \\
\hline \multicolumn{7}{|l|}{ Histological type } \\
\hline Differentiated & 29 & 40 & 0.080 & 35 & 34 & 0.3 \\
\hline Undifferentiated & 1 & 8 & & 3 & 6 & \\
\hline \multicolumn{7}{|c|}{ Median serum CEA level (ng/ml) } \\
\hline Before treatment & 6.6 & 21.05 & 0.045 & 7.25 & 22.35 & 0.07 \\
\hline 3 months later & 5.25 & 10.1 & 0.047 & 4.45 & 12.65 & 0.003 \\
\hline CEA reduction ratio & 0.70 & 0.61 & 0.4 & 0.50 & 0.76 & 0.033 \\
\hline Relative change & 0.65 & 0.92 & 0.029 & 0.48 & 1.01 & $<0.001$ \\
\hline
\end{tabular}

DDRP, DNA double-strand break repair protein; CEA, carcinoembryonic antigen.

MRE11 expression and clinical outcome. Positive nuclear staining of MRE11 was observed in $48(61.5 \%)$ of the 78 cases (Fig. 1A). The association between MRE11 expression and clinicopathological characteristics is shown in Table II. There was no significant association between MRE11 expression and age, tumor location or tumor size. Male gender and undifferentiated type tended to be associated with MRE11 positivity. There was no significant association between MRE11 expression and CEA reduction ratio. MRE11-negative cases had significantly better relative change compared with MRE1-positive cases. Thus, MRE11-negative cases achieved better size reduction of the target lesion when compared with MRE11-positive cases. The association between MRE11 expression and prognosis is shown in Fig. 2A. MRE11positive cases exhibited poorer PFS when compared with MRE11-negative cases, but no significant association was identified between MRE11 expression and PFS.

RAD51 expression and clinical outcome. Positive nuclear staining of RAD51 was observed in $40(51.2 \%)$ of the 78 cases (Fig. 1B). There was no significant association between RAD51 expression and age, gender, tumor location, tumor 
A

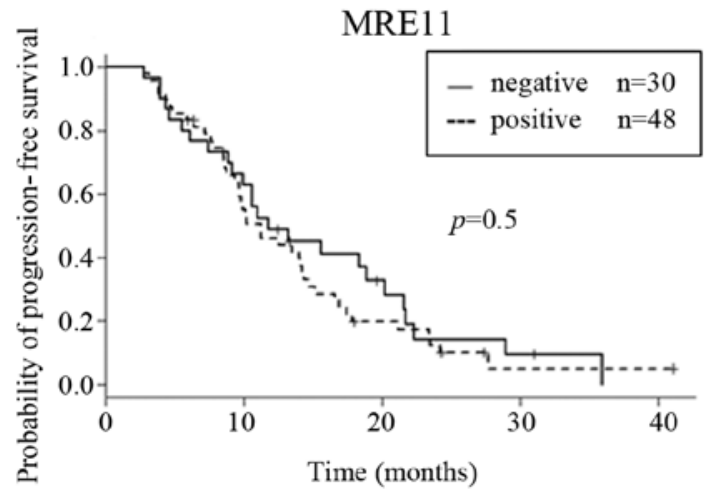

C

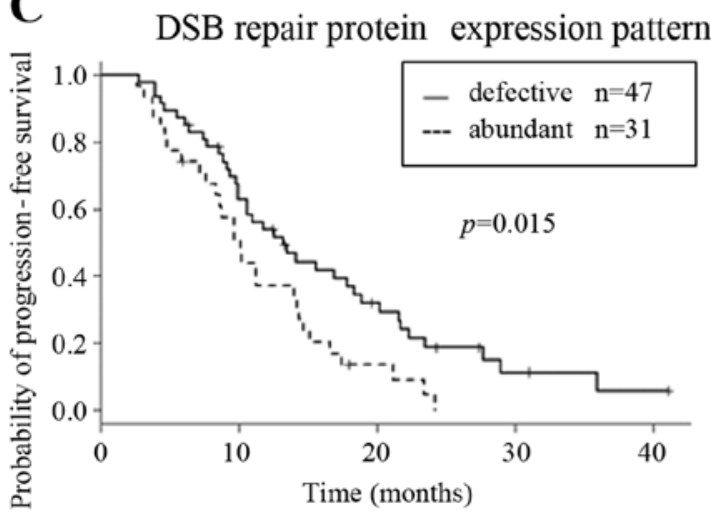

B

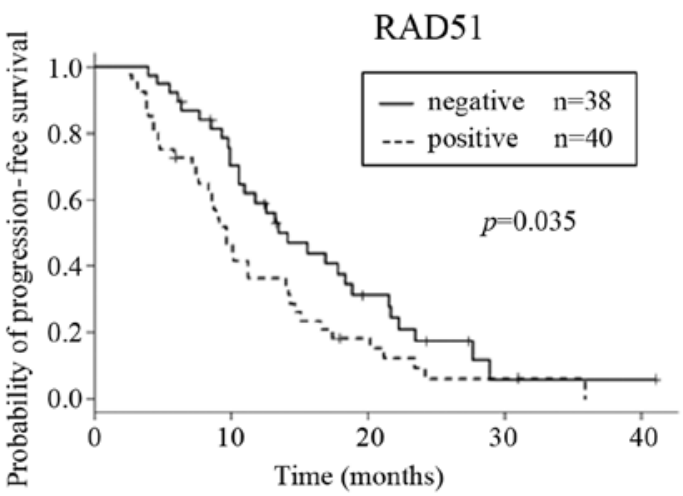

D

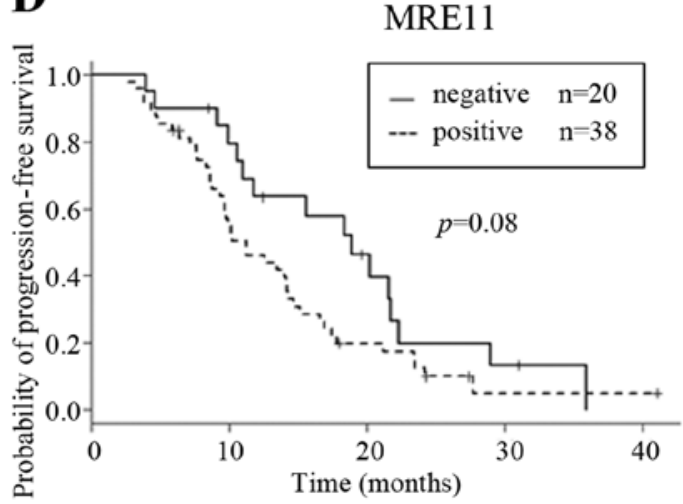

Figure 2. Kaplan-Meier progression-free survival curves of colon cancer patients. (A) MRE11 expression status in all cases (P=0.5). (B) RAD51 expression status in all cases $(\mathrm{P}=0.035)$. (C) DSB repair protein expression pattern in all cases $(\mathrm{P}=0.015)$. (D) MRE11 expression status in distal colon $(\mathrm{P}=0.077)$.

size or histological type (Table II). RAD51-negative cases had significantly better CEA reduction ratios and relative change. RAD51-positive cases had significantly poorer PFS when compared with RAD51-negative cases (Fig. 2B). However, for multivariate analysis, RAD51 was not an independent prognostic factor (Table III).

$D S B$ repair protein expression pattern. In the DSB repair pathway, the role of MRE11 and RAD51 are sequential. When one of either is defect, it may be impossible to recovery from DSBs. Therefore, we defined two groups. The 'defective pattern' is described as the state when expression of both MRE11 and RAD51 expression is negative or expression of either one of these protein is negative. The 'abundant pattern' is described as the state when expression of both proteins is positive. In addition, we investigated the association between the two groups and therapeutic effect. The association between expression patterns and clinical characteristics or chemotherapeutic effect is shown in Table IV. None of the examined clinicopathological characteristics correlated with the expression pattern. For the therapeutic effects, there was no significant difference between expression pattern and CEA reduction ratio. The defective pattern had significantly better relative change compared with the abundant pattern. As shown in Fig. 2C, the median PFS for the defective pattern and abundant pattern was 13.2 and 10.1 months, respectively, and there was a significant difference between the defective pattern and abundant pattern for PFS (Fig. 2C). Nonetheless, for the multivariate analysis, the expression pattern or RAD51 expression alone were not independent prognostic factors (Table III).

Distal colon cancer patients benefit more from these ex vivo tests. MRE11 mutations occur in $83.7 \%$ of MMR-defective primary colorectal cancers. MSI is displayed in $\sim 15 \%$ of colorectal cancer cases. We reviewed all subjects in the present study with the exception of one case of tumor localization to a site proximal to the splenic flexure due to the association of high-frequency MSI with this tumor site. In these cases, MRE11-negative cases exhibited longer PFS than the positive cases ( $\mathrm{P}=0.077$ ) (Fig. 2D). Moreover, by multivariate analysis, DSB repair protein expression pattern was an independent prognostic factor $(\mathrm{P}=0.036)$ (Table $\mathrm{V})$.

\section{Discussion}

The recent development of chemotherapies such as FOLFOX and FOLFIRI along with several molecular-targeting agents has markedly improved the survival of unresectable colorectal cancer patients. Previous studies have shown that the median survival time was prolonged to 11-26 months in unresectable advanced or recurrent colorectal cancer $(19,20)$. In the present study, we calculated the curative effect of chemotherapy by determining the correlations between DSB repair protein expression pattern and chemotherapeutic effect; those patients exhibiting better relative changes in 
Table III. Univariate and multivariate analyses for progression-free survival.

\begin{tabular}{lllll}
\hline & \multicolumn{2}{c}{ Univariate } & & Multivariate \\
\cline { 2 - 2 } Factor & $\begin{array}{l}\text { Median } \\
\text { PFS P-value }\end{array}$ & & $\begin{array}{c}(95 \% \mathrm{CI}) \\
\mathrm{HR}\end{array}$ & P-value \\
\hline
\end{tabular}

\begin{tabular}{|c|c|c|c|c|}
\hline \multicolumn{5}{|l|}{ Age (years) } \\
\hline$>60$ & 11.8 & \multicolumn{3}{|l|}{0.8} \\
\hline$\leq 60$ & 10.6 & & & \\
\hline \multicolumn{5}{|l|}{ Gender } \\
\hline Male & 13.2 & \multirow{2}{*}{\multicolumn{3}{|c|}{0.070}} \\
\hline Female & 10 & & & \\
\hline \multicolumn{5}{|l|}{ Location } \\
\hline Proximal & 9.3 & \multirow[t]{2}{*}{0.002} & $0.56(0.31-1.00)$ & 0.051 \\
\hline Distal & 13.5 & & & \\
\hline \multicolumn{5}{|c|}{ Tumor size (mm) } \\
\hline$<50$ & 11.3 & \multirow{2}{*}{\multicolumn{3}{|c|}{0.5}} \\
\hline$\geq 50$ & 11.3 & & & \\
\hline
\end{tabular}

Histology

Undifferentiated $\quad 11.8 \quad 0.1$

Differentiated $\quad 9.7$

Treatment cycles

$<10$

$\geq 10$

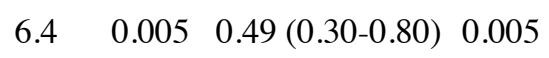$$
14.2
$$

CEA reduction ratio

$\begin{array}{lll}<0.6 & 11.3 & 0.4 \\ \geq 0.6 & 11.3\end{array}$

Relative change

\begin{tabular}{|c|c|c|c|}
\hline$<0.7$ & 18.4 & $<0.001$ & \multirow[t]{2}{*}{$2.53(1.39-4.62)$} \\
\hline$\geq 0.7$ & 9,0 & & \\
\hline
\end{tabular}

MRE11

$\begin{array}{lrrrr}\text { Negative } & 11.8 & 0.5 & & \\ \text { Positive } & 11.3 & & \\ \text { RAD51 } & & & & \\ \text { Negative } & 13.5 & 0.035 & 0.80(0.35-1.83) & 0.6 \\ \text { Positive } & 9.7 & & & \\ \text { DSB repair protein } & & & & \\ \text { expression pattern } & & & & \\ \text { Defective } & 13.2 & 0.015 & 1.39(0.58-3.34) & 0.5 \\ \text { Abundant } & 10.1 & & & \\ \end{array}$

HR, hazard ratio; PFS, progression-free survival; CI, confidence interval; DSB, double-strand break.

tumor size had longer survival times. According to a previous study, the chemotherapeutic effect by first-line treatment may be a prognostic factor. Therefore, it is necessary to detect biomarkers that predict the effect of first-line treatment to obtain further chemotherapeutic effects.

Oxaliplatin is a DNA intrastrand cross-linking agent and is frequently used to treat colorectal cancer that has spread.
Table IV. Relationship between the DSB protein expression pattern and clinicopathological characteristics.

\begin{tabular}{lccc}
\hline Factors & $\begin{array}{c}\text { Defective } \\
(\mathrm{n}=47)\end{array}$ & $\begin{array}{c}\text { Abundant } \\
(\mathrm{n}=31)\end{array}$ & P-value \\
\hline Median age (years) & 64 & 68 & 0.3 \\
Gender, $\mathrm{n}$ & & & \\
$\quad$ Male & 30 & 19 & 0.8 \\
Female & 17 & 12 & \\
Location, $\mathrm{n}$ & & & \\
$\quad$ Right & 13 & 7 & 0.8 \\
Left & 34 & 24 & \\
Median tumor size (mm) & 55 & 50 & 0.6 \\
Median treatment cycles & 11 & 8 & 0.1 \\
Histological type, $\mathrm{n}$ & & & \\
$\quad$ Differentiated & 44 & 25 & $0.08^{\mathrm{a}}$ \\
$\quad$ Undifferentiated & 3 & 6 & \\
Median serum CEA level & & & \\
(ng/ml) & & & \\
$\quad$ Before treatment & 7 & 24 & 0.009 \\
3 months later & 4.7 & 12.8 & 0.001 \\
CEA reduction ratio & 0.55 & 0.68 & 0.1 \\
Relative change & 0.5 & 1.02 & $<0.001$ \\
\hline DSB, DNA double-strand break. & & & \\
\hline
\end{tabular}

Table V. Univariate and multivariate analyses for PFS in the distal colon.

\begin{tabular}{|c|c|c|c|c|}
\hline \multirow[b]{2}{*}{ Factor } & \multicolumn{2}{|c|}{ Univariate } & \multicolumn{2}{|l|}{ Multivariate } \\
\hline & Median & P-value & $\mathrm{HR}(95 \% \mathrm{CI}) \quad \mathrm{P}$ & P-value \\
\hline \multicolumn{5}{|c|}{ Treatment cycles } \\
\hline$<10$ & 8.8 & 0.009 & $0.46(0.27-0.78)$ & 0.004 \\
\hline$\geq 10$ & 14.5 & & & \\
\hline \multicolumn{5}{|c|}{ CEA reduction ratio } \\
\hline$<0.6$ & 13.5 & 0.2 & & \\
\hline$\geq 0.6$ & 12.6 & & & \\
\hline \multicolumn{5}{|c|}{ Relative change } \\
\hline$<0.7$ & 18.9 & $<0.001$ & $2.23(1.17-4.24)$ & 0.014 \\
\hline$\geq 0.7$ & 9.7 & & & \\
\hline \multicolumn{5}{|l|}{ MRE11 } \\
\hline Negative & 18.9 & 0.077 & & \\
\hline Positive & 11.3 & & & \\
\hline \multicolumn{5}{|l|}{ RAD51 } \\
\hline Negative & 15.6 & 0.036 & $0.44(0.15-1.37)$ & 0.2 \\
\hline Positive & 10.1 & & & \\
\hline \multicolumn{5}{|c|}{$\begin{array}{l}\text { DSB repair protein } \\
\text { expression pattern }\end{array}$} \\
\hline Defective & 16.9 & 0.001 & $3.62(1.09-11.99)$ & 0.036 \\
\hline Abundant & 10.1 & & & \\
\hline
\end{tabular}

DSB, double-strand break. 

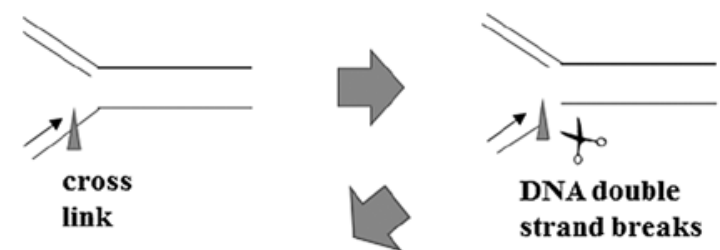

Homologous Recombination (HR)

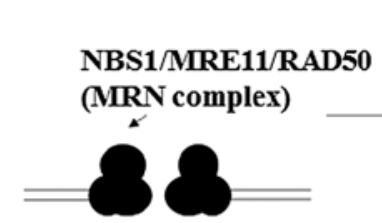

The primary sensor of DSBs

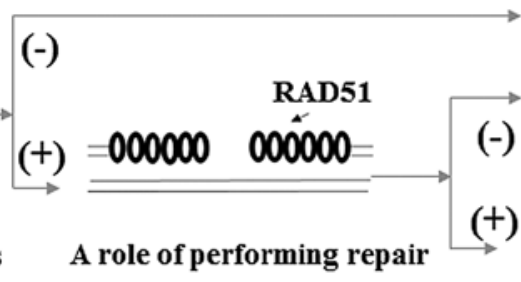

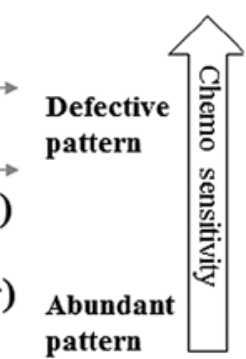

Figure 3. Schema of DNA double-strand breaks (DSBs) by cross-linking agents, the role of DSB repair proteins for homologous recombination and definition of DSB repair protein expression pattern. In the DSB repair pathway, the role of MRE11 and RAD51 are sequential. When expression of either is defective, it may be impossible to repair DNA DSBs. Therefore, we defined two groups. The 'defective pattern' is a state when levels of expression of MRE11 and RAD51 are negative or a state when expression of one of these proteins is negative. The 'abundant pattern' is the state when expression levels of both proteins are positive. We hypothesized that a defective pattern possesses higher sensitivity to chemotherapy than the abundant pattern.

The cytotoxic reaction of oxaliplatin is dependent on DSBs. In DSBs defective cases, the chemotherapeutic effect of oxaliplatin may be greater. MRE11 and RAD51 are important components of homologous recombination, which functions in the repair of DSB. In the present study, we examined the correlation between the expression of these proteins and the chemotherapeutic effect in colorectal cancer patients. RAD51 protein forms a helical nucleoprotein filament to promote DNA strand exchange and stimulate DNA-pairing activity, the basic steps of homologous recombination $(21,22)$. In the present study, patients negative for MRE11 or RAD51 expression obtained better size reduction of target lesions. We showed that RAD51-negative cases achieved longer survival times than positive cases. Several previous studies demonstrated that RAD51 expression is correlated with resistance to chemotherapy and survival in various types of cancer such as lung, breast and esophageal cancer (23-25).

MRE11 is the core component of the MRN complex, the primary sensor of DSBs $(12,13)$. In the present study, MRE11 expression was not an independent prognostic factor. The combined evaluation of MRE11, which acts as a sensor, and RAD51, which functions in repair, may lead to a better indication of the chemotherapeutic effect (Fig. 3). In fact, the relative change and PFS were significantly different between the defective pattern and abundant pattern, the expression pattern of DSB repair proteins.

We investigated the reason for the difference between MRE11 and RAD51 despite it also being a DSB repair protein, and postulated that some factors that may affect MRE11 alone intervened in the result. MRE11 mutations occur in $83.7 \%$ of MMR-defective primary colorectal cancers $(26,27)$. Microsatellite instability (MSI) is displayed by $\sim 15 \%$ of colorectal cancer cases, and high levels of MSI may be a predictive marker for lack of efficacy of fluorouracil-based therapy $(28,29)$. This raises the possibility that some MRE11negative patients have poor prognosis as a consequence of their MSI status. We reviewed the subjects of our study with the exception of one case of tumor localization to a site proximal to the splenic flexure due to the association of high-frequency MSI with this tumor site (6). In this instance, MRE11 expression tended to be related to $\mathrm{PFS}$, and DSB repair protein expression pattern is a factor that independently predicts PFS. In cases of tumor development in the distal colon, DSB repair protein expression may predict prognosis.

In the present study, we only examined cases with a targeted lesion to clarify associations with chemotherapeutic effect. Therefore, it is necessary to confirm expression in other cases. Moreover, we only investigated cases receiving oxaliplatin-based chemotherapy regimen as first-line treatment since there were few cases undergoing other regimens as first-line treatment. In future studies, we will investigate the association between the expression of DSB repair proteins and the chemotherapeutic effect for other regimens, and compare these findings with the results of the present study.

In conclusion, cases with a defective pattern of DSB repair protein expression may possess higher sensitivity to chemotherapy for colorectal cancer. The expression pattern of DSB repair proteins may be a useful prognostic indicator for colorectal cancer patients.

\section{Acknowledgements}

The authors would like to thank H. Ozeki, Y. Ohashi, and M. Asano for their secretarial assistance and N. Suzuki, a member of the Research Support Center Division of Clinical Science, for her technical assistance. The present study was supported in part by JSPS KAKENHI grant no. 25462065.

\section{References}

1. Tournigand C, André T, Achille E, Lledo G, Flesh M, MeryMignard D, Quinaux E, Couteau C, Buyse M, Ganem G, et al: FOLFIRI followed by FOLFOX6 or the reverse sequence in advanced colorectal cancer: A randomized GERCOR study. J Clin Oncol 22: 229-237, 2004. 
2. Yamaguchi S, Ogata H, Katsumata D, Nakajima M, Fujii T, Tsutsumi S, Asao T, Sasaki K, Kuwano H and Kato H: Early serum carcinoembryonic antigen reduction predicts tumor shrinkage and overall survival in colorectal cancer patients with distant metastasis, after primary surgery followed by mFOLFOX6 plus bevacizumab treatment. Hepatogastroenterology (In press).

3. Grothey A, Sargent D, Goldberg RM and Schmoll HJ: Survival of patients with advanced colorectal cancer improves with the availability of fluorouracil-leucovorin, irinotecan, and oxaliplatin in the course of treatment. J Clin Oncol 22: 1209-1214, 2004.

4. Saltz LB, Clarke S, Díaz-Rubio E, Scheithauer W, Figer A, Wong R, Koski S, Lichinitser M, Yang TS, Rivera F, et al: Bevacizumab in combination with oxaliplatin-based chemotherapy as first-line therapy in metastatic colorectal cancer: A randomized phase III study. J Clin Oncol 26: 2013-2019, 2008.

5. Van Cutsem E, Köhne CH, Hitre E, Zaluski J, Chang Chien CR, Makhson A, D'Haens G, Pintér T, Lim R, Bodoky G, et al: Cetuximab and chemotherapy as initial treatment for metastatic colorectal cancer. N Engl J Med 360: 1408-1417, 2009.

6. Ribic CM, Sargent DJ, Moore MJ, Thibodeau SN, French AJ, Goldberg RM, Hamilton SR, Laurent-Puig P, Gryfe R, Shepherd LE, et al: Tumor microsatellite-instability status as a predictor of benefit from fluorouracil-based adjuvant chemotherapy for colon cancer. N Engl J Med 349: 247-257, 2003.

7. Chiu SJ, Lee YJ, Hsu TS and Chen WS: Oxaliplatin-induced gamma-H2AX activation via both p53-dependent and -independent pathways but is not associated with cell cycle arrest in human colorectal cancer cells. Chem Biol Interact 182: 173-182, 2009.

8. Asakawa H, Koizumi H, Koike A, Takahashi M, Wu W, Iwase H, Fukuda $\mathrm{M}$ and Ohta T: Prediction of breast cancer sensitivity to neoadjuvant chemotherapy based on status of DNA damage repair proteins. Breast Cancer Res 12: R17, 2010.

9. Turner N, Tutt A and Ashworth A: Hallmarks of 'BRCAness' in sporadic cancers. Nat Rev Cancer 4: 814-819, 2004.

10. Chu G: Double strand break repair. J Biol Chem 272: 24097-24100, 1997.

11. Gallagher DJ, Konner JA, Bell-McGuinn KM, Bhatia J, Sabbatini P, Aghajanian CA, Offit K, Barakat RR, Spriggs DR and Kauff ND: Survival in epithelial ovarian cancer: A multivariate analysis incorporating $B R C A$ mutation status and platinum sensitivity. Ann Oncol 22: 1127-1132, 2011.

12. Moynahan ME, Cui TY and Jasin M: Homology-directed DNA repair, mitomycin-c resistance, and chromosome stability is restored with correction of a Brcal mutation. Cancer Res 61: 4842-4850, 2001.

13. Stracker TH and Petrini JH: The MRE11 complex: Starting from the ends. Nat Rev Mol Cell Biol 12: 90-103, 2011.

14. Williams RS, Williams JS and Tainer JA: Mre11-Rad50-Nbs1 is a keystone complex connecting DNA repair machinery, doublestrand break signaling, and the chromatin template. Biochem Cell Biol 85: 509-520, 2007.

15. Baumann P and West SC: Role of the human RAD51 protein in homologous recombination and double-stranded-break repair. Trends Biochem Sci 23: 247-251, 1998.

16. Slupianek A, Schmutte C, Tombline G, Nieborowska-Skorska M, Hoser G, Nowicki MO, Pierce AJ, Fishel R and Skorski T: BCR/ABL regulates mammalian RecA homologs, resulting in drug resistance. Mol Cell 8: 795-806, 2001.
17. Takenaka T, Yoshino I, Kouso H, Ohba T, Yohena T, Osoegawa A, Shoji F and Maehara Y: Combined evaluation of Rad51 and ERCC1 expressions for sensitivity to platinum agents in non-small cell lung cancer. Int J Cancer 121: 895-900, 2007.

18. Piessevaux H, Buyse M, Schlichting M, Van Cutsem E, Bokemeyer C, Heeger S and Tejpar S: Use of early tumor shrinkage to predict long-term outcome in metastatic colorectal cancer treated with cetuximab. J Clin Oncol 31: 3764-3775, 2013.

19. Yoshida M, Goto M, Kii T, Nishitani H, Kawabe S, Kuwakado S, Asaishi K, Miyamoto T and Higuchi K: Retrospective study as first-line chemotherapy combined anti-VEGF antibody with fluoropyrimidine for frail patients with unresectable or metastatic colorectal cancer. Digestion 87: 59-64, 2013.

20. Maeda K, Shibutani M, Otani H, Nagahara H, Sugano K, Ikeya T, Kubo N, Amano R, Kimura K, Muguruma K, et al: Low nutritional prognostic index correlates with poor survival in patients with stage IV colorectal cancer following palliative resection of the primary tumor. World J Surg 38: 1217-1222, 2014.

21. Thompson LH and Schild D: The contribution of homologous recombination in preserving genome integrity in mammalian cells. Biochimie 81: 87-105, 1999.

22. Sung $P$ and Robberson DL: DNA strand exchange mediated by a RAD51-ssDNA nucleoprotein filament with polarity opposite to that of RecA. Cell 82: 453-461, 1995.

23. Nakanoko T, Saeki H, Morita M, Nakashima Y, Ando K, Oki E, Ohga T, Kakeji Y, Toh Y and Maehara Y: Rad51 expression is a useful predictive factor for the efficacy of neoadjuvant chemoradiotherapy in squamous cell carcinoma of the esophagus. Ann Surg Oncol 21: 597-604, 2014.

24. Tsai MS, Kuo YH, Chiu YF, Su YC and Lin YW: Down-regulation of Rad51 expression overcomes drug resistance to gemcitabine in human non-small-cell lung cancer cells. J Pharmacol Exp Ther 335: 830-840, 2010.

25. Hannay JA, Liu J, Zhu QS, Bolshakov SV, Li L, Pisters PW, Lazar AJ, Yu D, Pollock RE and Lev D: Rad51 overexpression contributes to chemoresistance in human soft tissue sarcoma cells: A role for p53/activator protein 2 transcriptional regulation. Mol Cancer Ther 6: 1650-1660, 2007.

26. Giannini G, Rinaldi C, Ristori E, Ambrosini MI, Cerignoli F, Viel A, Bidoli E, Berni S, D'Amati G, Scambia G, et al: Mutations of an intronic repeat induce impaired MRE11 expression in primary human cancer with microsatellite instability. Oncogene 23: 2640-2647, 2004.

27. Vilar E, Bartnik CM, Stenzel SL, Raskin L, Ahn J, Moreno V, Mukherjee B, Iniesta MD, Morgan MA, Rennert G, et al: MRE11 deficiency increases sensitivity to poly(ADP-ribose) polymerase inhibition in microsatellite unstable colorectal cancers. Cancer Res 71: 2632-2642, 2011.

28. Sargent DJ, Marsoni S, Monges G, Thibodeau SN, Labianca R, Hamilton SR, French AJ, Kabat B, Foster NR, Torri V, et al: Defective mismatch repair as a predictive marker for lack of efficacy of fluorouracil-based adjuvant therapy in colon cancer. J Clin Oncol 28: 3219-3226, 2010.

29. Yamaguchi S, Ogata H, Katsumata D, Nakajima M, Fujii T, Tsutsumi S, Asao T, Sasaki K, Kuwano H and Kato H: MUTYHassociated colorectal cancer and adenomatous polyposis. Surg Today 44: 593-600, 2014. 